\title{
İkincil Yakıtların Çimento Üretimine Etkisi Üzerine Bir Araştırma: Klinker Kompozisyonu, Çimentonun Mukavemeti ve Sızdırma Özellikleri
}

\author{
A Study On The Effect Of Secondary Fuels On Cement \\ Production: Clinker Composition, Strength and Leaching \\ Properties of Cement
}

\author{
Gizem Eker Şanlı $1^{*} \mathbb{C}$, Hatice Ünlü ${ }^{2}{ }^{\circledR}$, \\ ${ }^{1}$ Bursa Uludağ Üniversitesi Mühendislik Fakütesi, Çevre Mühendisliği Bölümü, Bursa TÜRKIYY \\ 2 Bursa Büyükşehir Belediyesi, Çevre Koruma Daire Başkanlığı, Bursa TÜRKIYE \\ Sorumlu Yazar / Corresponding Author*: geker@uludag.edu.tr \\ Geliș Tarihi / Received: 08.01.2020 Araștırma Makalesi/Research Article \\ Kabul Tarihi / Accepted: 20.05.2020 DOI:10.21205/deufmd.2020226619 \\ Atıfsekli/How to cite: EKER SANLI, G., UNLU, H. (2020). İkincil Yakıtların Çimento Üretimine Etkisi Üzerine Bir Araştırma: Klinker \\ Kompozisyonu, Çimentonun Mukavemeti ve Sizdırma Özellikleri. DEUFMD 22(66), 851-860.
}

\section{Öz}

Bu çalışmada, bir çimento fabrikasında atık lastik ve atık yağın çimento üretiminde petrokok ikamesi olarak kullanımı araştırılmıştır. \%10 atık lastik ve \%3 ve \%5 atık yağ ile petrokok tam ölçekli çimento döner fırında yakılmıştır. Atık lastik ve yağ kullanımıyla klinkerin kimyasal özelliklerinin değişmediği, özgül yüzey alanının yaklaşık \%5 arttığı belirlenmiştir. Çimento harç numuneleri hazırlanmış ve 3, 7, 28 ve 56 günlük kürleme sürelerinden sonra serbest basınç dayanımları (UCS) ölçülmüştür. İkincil yakıt kullanılarak üretilen Portland çimentosu örneklerinin UCS değerlerinin 56 günlük kür süresi sonunda petrokok kullanılarak üretilen çimento sonuçlarına eşit olduğu görülmüştür. $\mathrm{Zn}, \mathrm{Cr}, \mathrm{Pb}$ ve $\mathrm{Cd}$ için Toksisite Özellikleri Sızdırma Prosedürüne (TCLP) göre sızıntı suyuna geçen konsantrasyonlar belirlenmiştir. En yüksek ağır metal konsantrasyonları 1,27 mg/l Zn, 0,080 mg/l Cr, 0,040 mg/l Pb ve $0,003 \mathrm{mg} / \mathrm{l}$ Cd olarak ölçülmüştür. Elde edilen değerler Amerika Çevre Koruma Ajansı (USEPA) atık depolama sınır değerlerinden düşüktür. Bu veriler ışığında, $\% 10$ atık lastik ile $\% 5$ atık yağın ikincil yakıt olarak kullanılmasının, çimentonun fiziksel ve kimyasal özelliklerinde önemli değişikliklere neden olmadığı ve çevre üzerinde olumsuz bir etkisinin olmadığı sonucuna varılmıștır.

Anahtar Kelimeler: Atık Lastik, Atık Yağ, İkincil Yakıt, Portland Çimento, Serbest Basınç Dayanımı, Sizma

\section{Abstract}

In the present study, use of waste tyre and waste oil in a cement factory as a petrococke substitutes were investigated. $10 \%$ waste tyre along with $3 \%$ and $5 \%$ waste oil as petrococke substitutes were 
combusted in a full-scale cement rotary kiln. It was determined that chemical characteristics of clinker did not change while the specific surface area increased aproximately $5 \%$ with the use of waste tyre and oil. The cement mortar samples were prepared and unconfined compressive strengths (UCS) were measured after the curing periods of $3,7,28$, and 56 days. It was seen that UCS values of the Portland cement samples produced with the using of secondary fuel was equal to the results of the cement produced using petrococke at the end of the 56 curing days. $\mathrm{Zn}, \mathrm{Cr}, \mathrm{Pb}$ and $\mathrm{Cd}$ were exctracted from mortar samples according to the Toxicity Characteristics Leaching Procedure (TCLP). The highest heavy metal concentrations in the leachates were measured as $1.27 \mathrm{mg} / \mathrm{l} \mathrm{Zn}, 0.080 \mathrm{mg} / \mathrm{l} \mathrm{Cr}$, $0.040 \mathrm{mg} / \mathrm{l} \mathrm{Pb}$ and $0.003 \mathrm{mg} / \mathrm{l} \mathrm{Cd}$. Leachates metal concentrations were conformed with the Enivironmental Protection Agency (USEPA) waste landfilling limits. It was concluded that using of $10 \%$ waste tyre along with $5 \%$ waste oil as a secondary fuel did not cause considerable changes in the physical and chemical characteristics of the cement and did not have any negative impact on environment.

Keywords: Waste Tyre, Waste Oil, Secondary Fuel, Portland Cement, Unconfined Compressive Strength, Leaching

\section{Giriș}

Çimento sanayi, yüksek enerji ihtiyacı olan sektörler arasında yer almakta olup [1] bir ton çimentonun üretilebilmesi için yaklaşık olarak 10 milyon $\mathrm{kj} / \mathrm{kg}^{\prime} \mathrm{llk}$ enerjiye ihtiyaç duyulmaktadır [2]. Kömür, doğal gaz, yağ ve petrokok gibi enerji kaynakları, çimento fabrikalarında klinker üretimi esnasında kullanılan başlıca konvansiyonel yakıtlar arasında yer almakta ve bu yakıtlar için ayrılan bütçe işletme masraflarının \%30-40'lık kısmına karşılık gelmektedir. Yakıt maliyetlerinin düșürülmesi ve enerji kaynaklarının korunması için çimento üretiminde ikincil yakıtların kullanımı mümkün görülmektedir. $\mathrm{Bu}$ amaçla, enerji içeriği yüksek olan atık yağlar, kullanılmış lastikler, solventler ve kentsel atıksu aritma çamurları ikincil yakıt olarak kullanılabilmektedir [3-7].

Atık lastikler, Tehlikeli Atıkların Kontrolü Yönetmeliği'ne göre özel atık olarak tanımlanmaktadır. $\mathrm{Bu}$ atıklar, kömür gibi konvansiyonel yakıtlardan daha yüksek isıl değere sahip olup çimento fabrikalarında ikincil yakıt olarak kullanılabilmektedir [4,810]. Lastiklerin ikincil yakıt olarak kullanımıyla ilgili uygulamalar Amerika'da ve Avrupa ülkelerindeki çimento fabrikalarında uzun yıllardır sürdürülmektedir [1]. Son yıllarda ülkemizde de ikincil yakıt kullanmak üzere lisans almış çimento fabrikalarında tam ölçekli uygulamalara yer verilmeye başlanmıştır.
Yağlar, belli bir kullanım süresi sonunda kimyasal ve fiziksel olarak kirlenerek atık haline gelmektedir. Ülkemizde atık yağlar, ağır metal içerikleri ve organik bileşenleri esas alınarak sınıflandırılmaktadır [11]. Buna göre I. ve II. kategori'ye giren atık yağlar lisanslı tesislerde ikincil yakıt olarak kullanılabilir [10] Çimento firınlarındaki yüksek sıcaklık değerleri, uzun işlem süresi ve oksitleyici ortam sayesinde, atıkların organik içerikleri yanmaktadır. Atık içerisindeki ağır metaller ve diğer inorganik bileşikler ise silikatlarla birleşmekte veya çeşitli mekanizmalarla klinker içerisinde tutularak çevreye taşınımları engellenmektedir [12].

Literatürde yer alan çalışmalarda, atık yakıt kullanımının, emisyon oluşumu $[13,14]$ ve çimento özellikleri $[3,12,15]$ üzerindeki etkileri incelenmiştir. Ayrıca atık yakıt kullanımıyla çimento yapısındaki ağır metal miktarlarının değişimi izlenmiştir [3]. Ancak, çimentodan çevreye salınan ağır metaller konusunda yapılan çalışmalar sınırlı sayıdadır. Üretilen çimentonun tehlikesiz bir ürün olarak değerlendirilebilmesi için, ağır metalleri sıdırma potansiyellerinin bilinmesi gerekmektedir. Ağır metallerin çimentodan çevreye salınımları, USEPA tarafından önerilen Toksisite Karakteristikleri Sızdırma Prosedürü (TCLP) kullanılarak tespit edilir. Sızıntı suyundaki ağır metal konsantrasyonlarının USEPA atık depolanabilirliği limit değerlerini aşmaması durumunda, atıkların ikincil yakıt 
olarak kullanımında bir sakınca olmadığ sonucuna varılabilir.

Bu çalışmada, atık lastiklerin ve atık yağların, çimento üretiminde ikincil yakıt olarak kullanımının, çimentonun kimyasal kompozisyonu, fiziksel özellikleri ve basınç dayanımı değerleri üzerindeki etkisi incelenmiş, üretilen çimentoların ağır metalleri çevreye sızdırma potansiyelleri belirlenmiştir.

\section{Materyal ve Metot}

$\mathrm{Bu}$ çalışmada, konvansiyonel yakıt olan petrokok yerine ikincil yakıt olarak, atık lastikler ve atık yağlar kullanılmıştır. Atık lastiğin, petrokokun ve atık yağın özellikleri sirasiyla Tablo 1 ve Tablo 2' de verilmiștir.

Atık lastikler, Tehlikeli Atıkların Kontrolü Yönetmeliği'nde Madde 48'de özel atıklar olarak değerlendirilmiștir [16]. Ayrıca Basel konvansiyonuna göre Y23 Zn içeriğinden ötürü tehlikelilik özelliği taşıdığı tespit edilmiştir [8]. Çalışmamızda kullanılan atık yağ, Atık Yağların Kontrolü Yönetmeliği'ne göre analiz edilmiş ve II. Kategori yağ sınıfında yer aldığı tespit edilmiştir. Atık lastik ve atık yağ, tam ölçekli bir çimento fabrikasında, ikincil yakıt olarak döner fırına beslenmiştir. Firınlarda üretilen klinkerlere, ağırlıkça \%5 oranında $\mathrm{CaSO}_{4} .2 \mathrm{H}_{2} \mathrm{O}$ (alçıtaşı) ilave edilerek Portland çimentosu elde edilmiştir. Üretilen klinkerlerin kimyasal kompozisyonları XRF 9800 XP, spesifik yüzey alanları ise incelik testi-hava geçirimlilik metoduna göre [17] TONIC TECHNIC 72071 cihazıyla belirlenmiştir. Portland çimentosu, Rilem Cembureau Standart Kum [17] ve su kullanılarak harç numuneleri hazırlanmıştır. Referans numune, yakıt olarak ağırlıkça \%100 petrokok kullanılarak üretilen çimento ile hazırlanırken, diğer numuneler sırasıyla, \%10 lastik $+\% 90$ petrokok, \%10 lastik $+\% 3$ yağ + $\% 87$ petrokok, \%10 lastik $+\% 5$ yağ $+\% 85$ petrokok kullanılarak üretilen çimentolarla hazırlanmıştır. Harç numuneleri için $40 \mathrm{~mm} \mathrm{x}$ $40 \mathrm{~mm} \times 160 \mathrm{~mm}$ olan prizmatik kalıplar kullanılmış ve su/çimento oranı 0,5'te sabit tutulmuştur. Bir gün sonra kalıptan çıkarılan numunelerde $3,7,28$ ve 56 günlük su kürü süreleri sonunda basınç dayanımı değerleri ESEL ESL.25.001.B-015 TEMAK $250 \mathrm{kN}$ beton basınç dayanımı test presinde ölçülmüştür. 28 gün sonunda numuneler, USEPA'in tehlikeli atıkların depolanabilirliği için önerdiği TCLP prosedürüne göre özütlenmiştir. Özütlenen numunelerde $\mathrm{Zn}, \mathrm{Cr}, \mathrm{Pb}$ ve $\mathrm{Cd}$ konsantrasyonları ICP-OES Viston-MPX cihazıyla ölçülmüştür.

Tablo 1. Atık lastiğin ve petrokokun özellikleri

\begin{tabular}{lclllc}
\hline \multicolumn{2}{c}{ Atık Lastik } & \multicolumn{2}{c}{ Atık Lastik } & \multicolumn{2}{c}{ Petrokok } \\
\hline Parametre & $\mathbf{\%}$ & Parametre & $\%$ & Parametre & $\%$ \\
\hline Karbon & 83,87 & $\mathrm{Zn}$ & 1,52 & Nem & 8,45 \\
Hidrojen & 7,09 & Nem & 0,62 & Kül & 0,52 \\
Nitrojen & 0,24 & Kül & 4,78 & $\begin{array}{l}\text { Toplam } \\
\text { Kükürt }\end{array}$ & 4,84 \\
Sülfür & 1,23 & Isll Değer & $\begin{array}{c}37798 \\
\text { kj/kg }\end{array}$ & Uçucu Madde & 12,05 \\
Oksijen & 2,17 & & & Isıl Değer & $32438 \mathrm{kj} / \mathrm{kg}$ \\
\hline
\end{tabular}


DEÜ FMD 22(66), 851-859, 2020

Tablo 2. Atık yağın özellikleri

kategoride değerlendirilmiștir. Atık yağın 9,66

\begin{tabular}{lllll}
\hline & \multirow{2}{*}{$\begin{array}{l}\text { Ölçülen } \\
\text { mg/l }\end{array}$} & I. Karametre & & \multicolumn{3}{c}{ Müsaade Edilen Sinır Değerleri } \\
\cline { 3 - 5 } & 0,63 & $<5 \mathrm{mg} / \mathrm{l}$ & $5 \mathrm{mg} / \mathrm{l}$ & $>5 \mathrm{mg} / \mathrm{l}$ \\
\hline Arsenik & 0,20 & $<2 \mathrm{mg} / \mathrm{l}$ & $2 \mathrm{mg} / \mathrm{l}$ & $>2 \mathrm{mg} / \mathrm{l}$ \\
Kadmiyum & 9,66 & $<10 \mathrm{mg} / \mathrm{l}$ & $10 \mathrm{mg} / \mathrm{l}$ & $>10 \mathrm{mg} / \mathrm{l}$ \\
Krom & 48,6 & $<200 \mathrm{mg} / \mathrm{l}$ & $2000 \mathrm{mg} / \mathrm{l}$ & $>2000 \mathrm{mg} / \mathrm{l}$ \\
Klorür & 2,0 & $<100 \mathrm{mg} / \mathrm{l}$ & $100 \mathrm{mg} / \mathrm{l}$ & $>100 \mathrm{mg} / \mathrm{l}$ \\
Kurşun & 399,6 & $<200 \mathrm{mg} / \mathrm{l}$ & $2000 \mathrm{mg} / \mathrm{l}$ & $>2000 \mathrm{mg} / \mathrm{l}$ \\
Toplam Halojenler & & & - & - \\
Isll değer (kj/kg) & 26000 & - & &
\end{tabular}

\section{Bulgular ve Tartışma}

\subsection{Atık Lastik ve Atık Yağın Özellikleri}

İkincil yakıtların ısıl değerinin minimum $15000 \mathrm{kj} / \mathrm{kg}$ olması istenmektedir [2,8]. Atık lastiğin isıl değeri $37798 \mathrm{kj} / \mathrm{kg}$ olup limit değeri sağlarken, ağırlıkça \%83 seviyesindeki karbon içeriğinin de yanma özelliklerini olumlu etkilediği görülmüștür. Atık lastiğin yapısında ağır metal olarak ağırlıkça \%1,20 Zn tespit edilmiş ve bunun lastikteki çelik kemerlerden kaynaklandığı düşünülmüştür [3].

Sülfür içeriği ise \%1,23 olup literatürdeki atık lastik sülfür değerleriyle (\%2) paralellik göstermiştir. Yakıt içerisindeki sülfür, $\mathrm{KCl}$, $\mathrm{K}_{2} \mathrm{SO}_{4}, \mathrm{Na}_{2} \mathrm{SO}_{4}$ gibi tuzların firın içerisinde halkalar oluşturmasını tetikleyerek fırının tıkanmasına ve çalıșma koşullarının olumsuz etkilenmesine neden olabilmektedir. $\mathrm{Bu}$ nedenle yakitların yüksek oranlarda sülfür içermesi istenmemektedir $\quad[3,8]$. Çalışmamızda, yerinde yapılan incelemelerde, tam ölçekli fırının, lastik içerisindeki mevcut sülfür içeriğinden olumsuz etkilenmediği, dolayısıyla mevcut sülfür içeriğinin herhangi bir problem teșkil etmediği görülmüștür.

Tehlikeli Atıkların Kontrolü Yönetmeliği'nde kategori II atık yağlarının da ilave yakıt olarak kullanılabileceği belirtilmiştir [16]. Çalışmamızda kullanılan atık yağ da bu $\mathrm{mg} / \mathrm{l} \mathrm{Cr}$ ve 2,00 mg/l Pb içerdiği tespit edilmiş olup ağır metal içeriğinin, yağın etkinliğini arttırmak için kullanılan katkı maddelerinden kaynaklandığı düșünülmüștür. Atık yağın tipik ısl değerinin $26000 \mathrm{~kJ} / \mathrm{kg}$ olup $15000 \mathrm{kj} / \mathrm{kg}$ sınır değeri sağladığı görülmüştür.

\subsection{Klinkerlerin Kimyasal Kompozisyonları}

Üretilen klinkerlerin kimyasal analiz sonuçları Tablo 3'te verilmiștir [18]. TS EN 197-1 standardında izin verilen $\mathrm{Cl}^{-}$miktarı maksimum ağırlıkça \%0,1'dir. Referans numunede ve atı yakıt kullanilan numunelerde, $\mathrm{Cl}^{-}$miktarı sınır değerin altında kalmış ve atık lastik ile atık yağ kullanımının klinkerin $\mathrm{Cl}^{-}$içeriğini arttırmadığı görülmüștür. Buna dayanılarak atık yakıt kullanımının korozyonu arttırıcı bir etkisinin bulunmadığ sonucuna varılmıştır. $\mathrm{SO}_{3}$ içeriğinin, tüm numunelerde TS EN 197-1'de sinır değeri olan $\% 4$ 'ten düşük olduğu ve atık yakıt kullanımıyla klinkerin $\mathrm{SO}_{3}$ içeriğinde kayda değer bir değişim olmadığı tespit edilmiştir. Çimento içerisinde yüksek miktarda $\mathrm{MgO}$ varlığında, $\mathrm{Ca}(\mathrm{OH})_{2}$ yerine $\mathrm{Mg}(\mathrm{OH})_{2}$ oluşumu gerçekleşmektedir. $\operatorname{Mg}(\mathrm{OH})_{2}$ 'de sertleşen çimentonun kırılganlaşmasına neden olmaktadır [19]. Atık yakıt kullanımıyla klinkerdeki MgO oranının azaldığı görülmüştür. Conner [20] tarafından bildirildiğine göre, tipik MgO içeriği \%1,4, CaO içeriği \%65 seviyelerindedir. Sunulan çalışmada üretilen klinker numunelerinde MgO oranı \%0,94-\%0,99 ve CaO içeriği de yaklaşık 
DEÜ FMD 22(66), 851-859, 2020

\%65 seviyelerinde olup tipik çimento özelliklerini tașıdığı görülmüștür. Genel olarak, klinkerin kimyasal kompozisyonu değerlendirildiğinde atık lastik ve atık yağ kullanımının klinkerin kimyasal özellikleri üzerinde olumsuz bir etkisinin olmadığı sonucuna varılmıștır.

Tablo3.Klinkerlerin kimyasal kompozisyonları

\begin{tabular}{|c|c|c|c|c|}
\hline & Çimento & $\begin{array}{c}\% 10 \\
\text { Lastik }\end{array}$ & $\begin{array}{c}\text { \%10 } \\
\text { Lastik+ }\end{array}$ & $\begin{array}{c}\% 10 \\
\text { Lastik+ }\end{array}$ \\
\hline $\mathrm{CaO}$ & 65,86 & 65,04 & 65,39 & 65,62 \\
\hline $\mathrm{SiO}_{2}$ & 21,08 & 21,55 & 21,28 & 21,26 \\
\hline $\mathrm{Al}_{2} \mathrm{O}_{3}$ & 5,34 & 5,23 & 5,18 & 5,24 \\
\hline $\mathrm{Fe}_{2} \mathrm{O}_{3}$ & 3,74 & 3,83 & 3,88 & 3,71 \\
\hline Mg0 & 0,99 & 0,94 & 0,97 & 0,95 \\
\hline $\mathbf{K}_{2} \mathbf{O}$ & 0,93 & 1,06 & 0,96 & 1,01 \\
\hline $\mathrm{Cl}$ & 0,03 & 0,03 & 0,03 & 0,03 \\
\hline $\mathrm{Na}_{2} \mathrm{O}$ & 0,30 & 0,30 & 0,30 & 0,30 \\
\hline $\mathbf{T i}_{2} \mathbf{O}$ & 0,22 & 0,21 & 0,21 & 0,22 \\
\hline $\mathrm{SO}_{3}$ & 1,41 & 1,43 & 1,34 & 1,46 \\
\hline MnO & 0,00 & 0,00 & 0,00 & 0,00 \\
\hline
\end{tabular}

Tablo 4'te görüldüğü üzere atık lastik ve atık yağ kullanılan numunelerde $\mathrm{C}_{3} \mathrm{~S}$ ve $\mathrm{C}_{2} \mathrm{~S}$ toplamının yaklașık \%72 olduğu ve referans numunedeki toplam değerden düşük olmadığı görülmüștür.

Literatürde, tipik bir Portland çimentosu için ağırlıkça $\mathrm{C}_{3} \mathrm{~S}$ ve $\mathrm{C}_{2} \mathrm{~S}$ toplamı $\% 72$ olarak verilmektedir [20]. Bu oran, atık yakıt kullanarak üretmiş olduğumuz tüm çimento numunelerinde sağlanmıștır.
Tablo 4.Klinkerlerin mineral kompozisyonu

\begin{tabular}{ccccc}
\hline $\begin{array}{c}\text { Portland } \\
\text { Çimentosu }\end{array}$ & $\mathrm{C}_{3} \mathrm{~S}$ & $\mathrm{C}_{2} \mathrm{~S}$ & $\mathrm{C}_{3} \mathrm{~A}$ & $\mathrm{C}_{4} \mathrm{AF}$ \\
\hline $\begin{array}{c}\text { \%10 Lastik } \\
\text { + \%0 Yağ }\end{array}$ & 59,29 & 15,71 & 7,81 & 11,39 \\
& & & & \\
$\begin{array}{c}\text { \%10 Lastik } \\
\text { +\%3 Yağ }\end{array}$ & 49,73 & 24,27 & 7,38 & 11,66 \\
$\begin{array}{c}\text { \%10 Lastik } \\
\text { +\%5 Yağ }\end{array}$ & 54,80 & 19,57 & 7,16 & 11,40 \\
\hline
\end{tabular}

$\mathrm{C}_{3} \mathrm{~A}$ hidratasyonun ilk aşamasında priz alma prosesini etkilerken basınç dayanımı gelişiminde ise esas olarak çimento yapısındaki $\mathrm{C}_{3} \mathrm{~S}$ ve $\mathrm{C}_{2} \mathrm{~S}$ etkilidir [20]. $\mathrm{C}_{3} \mathrm{~S}$ ilk dört haftalık süreçte, $\mathrm{C}_{2} \mathrm{~S}^{\prime}$ in hidrate olması da özellikle dört haftadan sonraki periyotta, katılaşan çimentonun basınç dayanımı gelişiminde etkili olmaktadır [19].

\subsection{Basınç Dayanımı Değerlerindeki Değişim}

Atık lastik ve yağın, çimentonun basınç dayanımı üzerindeki etkileri Şekil 1'de görülmektedir. \%10 oranında atık lastik içeren numunede 28 gün sonundaki basınç dayanımı değerlerinin, referans numune sonucunun \%91'ine ulaștığı görülmektedir.

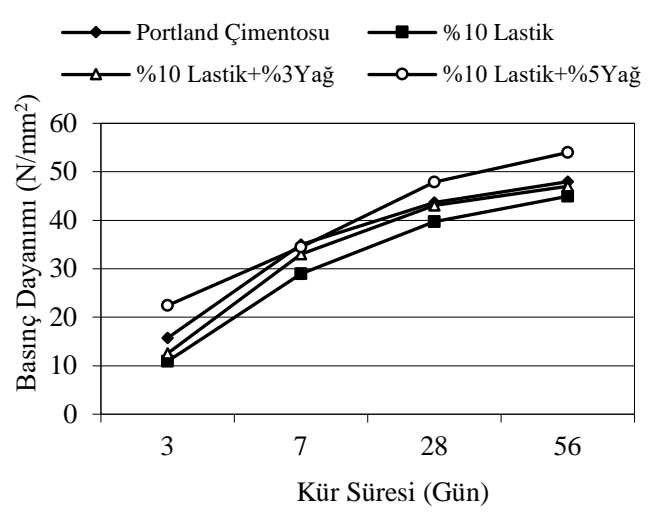

Şekil 1. Atık yakıt kullanımıyla basınç dayanımı değerlerindeki değișim 
Literatürde yer alan bir çalıșmada, ağırlıkça $\% 6$ oranında atık lastiğin ikincil yakıt olarak kullanılmasıyla, 7. günden itibaren referans numuneden daha yüksek basınç dayanımı sonuçlarının elde edildiği görülmüștür [3]. Benzer şekilde, atık lastiklerin, çimentonun mekanik özellikleri üzerindeki etkisinin incelendiği çalışmalarda basınç dayanımı değerlerinin lastik kullanımıyla yükseldiği tespit edilmiştir [15]. \%10 atık lastikle birlikte $\% 5$ atık yağ kullanımıyla 28 günlük basınç dayanımı değerinin referans numune sonucunun $\% 10$ üzerine çıktığl tespit edilmiştir.

Çinko, hidratasyonun ilk aşamalarında çimento tanecikleri etrafında, kalsiyum çinko zinkanat

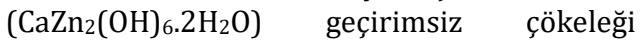
olușturarak, reaksiyonların yavașlamasına neden olmaktadır [21]. Ancak uzun vadede Zn'nun, hidroksit formunda C-S-H tarafindan tutulması beklenir [20]. Çalıșmamızda, \%10 atık lastik içeren numunelerin 3 günlük basınç dayanımı sonuçlarının referans numuneye nazaran \%30 düșük çlkmasının lastiğin $\mathrm{Zn}$ içeriğinden kaynaklandığı düşünülmektedir. 56 günlük kür süresi sonunda, $\% 10$ atık lastik içeren numunenin basınç dayanımı sonucunun, referans numune sonucuna ulaştığ görülmektedir. Buradan yola çlkarak, uzun vadede, Zn'nun hidrate fazlarda tutulduğu ve çimentonun basınç dayanımı özelliklerini olumsuz etkilemediği sonucuna varılmıştır.

$\% 10$ atık lastikle birlikte \%3-5 oranlarında atık yağ kullanımıyla, basınç dayanımı değerlerinde, tüm kür sürelerinde, referans numuneye göre ortalama \%12'lik bir artıș olmuştur. Basınç dayanımı değerlerinin yükselmesinin başlıca nedeninin, atık yağın $\mathrm{Cr}$ içeriği olduğu düșünülmektedir. Atık yağ, ağır metal olarak $\mathrm{Cr}$ ile birlikte $2 \mathrm{mg} / \mathrm{l} \mathrm{Pb}$ içermektedir. Pb'nun da Zn gibi hidratasyon prosesini geciktirici etkisi vardır [22]. Ancak, atık yağın $\mathrm{Pb}$ içeriğinin $\mathrm{Cr}$ 'dan düșük olması sebebiyle bu etkisinin gözlenmediği görülmüştür. Basınç dayanımı sonuçlarına dayanılarak $\mathrm{Cr}$ ve $\mathrm{Pb}$ içeren atık yağın, ağır metal içeriğinin çimentonun basınç dayanımını olumsuz etkilemediği sonucuna varılmıştır. Birim ağırlıktaki çimento taneciğinin kapladığı yüzey alanı olarak ifade edilen spesifik yüzey alanı (Blaine), çimentonun basınç dayanımını etkileyen fiziksel parametrelerdendir. Katkısız çimentonun Blaine değeri $3090 \mathrm{~cm}^{2} / \mathrm{g}$ iken atık lastik ve/veya atık yağ içeren örneklerde bu değer 3140 ile $3210 \mathrm{~cm}^{2} / \mathrm{g}$ arasında değişim göstermiştir. Atık lastik ve atık yă̆ kullanımıyla üretilen çimentoların spesifik yüzey alanlarında herhangi bir düşüş olmadığı görülmektedir. Atık yakıt kullanılan numunelerin Blaine sonuçları, referans numune sonuçlarından yaklaşık \%3 yüksek çıkmıştır. Çimentonun yüksek spesifik yüzey alanı, çimento tanecikleri ile su arasındaki teması arttırarak hidratasyonu hızlandırmakta, basınç dayanımı gelişimini olumlu etkilemektedir [20]. Çalışmamızda, atık lastik ve atık yağ içeren çimento numunelerinin spesifik yüzey alanı değerlerinin, uzun vadede referans çimento numunesiyle eș değer basınç dayanımı değerlerinin elde edilmesini sağladığı düșünülmektedir. Ayrıca atık lastik ve yağ kullanımıyla spesifik yüzey alanın düşmemiş olması, ağır metallerin, çok sayıda yeni kristal faz olușturmaktan ziyade mevcut kristal yapılar tarafından tutulduğuna işaret etmektedir [15].

\subsection{Ağır Metallerin Sızma Özellikleri}

Şekil 2'de TCLP ekstraksiyonu sonrasında sizıntı suyuna geçen $\mathrm{Zn}, \mathrm{Pb}, \mathrm{Cr}$ ve $\mathrm{Cd}$ konsantrasyonlarının atık lastik ve atık yağ kullanımıyla değişimi gösterilmektedir. Referans numuneden sızıntı suyuna geçen $\mathrm{Zn}$ konsantrasyonunun $0,5 \mathrm{mg} / \mathrm{l}$ olduğu tespit edilmiştir. Atık lastik ve atık yağ kullanımının sizıntı suyuna geçen Zn konsantrasyonunu $\% 100$ arttırarak $1 \mathrm{mg} / \mathrm{l}$ 'ye kadar çıkardığ ancak bu değerin USEPA atık depolanabilirliği sınır değeri olan 4,3 mg/l'den [23] düşük olduğu görülmüștür (Şekil 2a). Çimentonun hidratasyonu esnasında olușan $\mathrm{Ca}(\mathrm{OH})_{2}$ ve C-S$\mathrm{H}$ fazlarının sağladığı yüksek tamponlama kapasitesi Zn'nun çözünmeyen bileşik formunda, çimento içerisinde tutulabilmesi için uygun şartların oluşmasını sağlamaktadır [20]. Hidratasyonun ilk așamalarında pH değerinin 13 dolaylarında olması beklenir. Zn, bu $\mathrm{pH}$ değerinde, kalsiyum çinko zinkanat bileșiğini oluşturur. Ancak belli bir süre sonra, $\mathrm{Ca}(\mathrm{OH})_{2}$ 'in tüketilmesiyle $\mathrm{pH} 11$ 'e düsser ve kalsiyum çinko zinkanat bileșiği $\mathrm{Zn}(\mathrm{OH})_{2}{ }^{\prime} \mathrm{e}$ dönüșür. Atık lastik ve atık yağ kullanımıyla klinkerin yapısına giren $\mathrm{Zn}, \mathrm{Zn}(\mathrm{OH})_{2}$ formunda C-S-H tarafindan sorblanır veya $\mathrm{C}_{4} \mathrm{AF}$ 'nin hidratasyonu sonucunda oluşan kalsiyum 
alümina hidratların içinde tutulur. Bizim çalışmamızda, çinkonun, fiziksel enkapsülasyon mekanizmasından ziyade yukarıdaki gibi kimyasal stabilizasyonla tutulduğu [21] böylelikle, fiziksel baskılara maruz kalan katılaşmış çimentodan çevreye salınan Zn miktarının minimum seviyelere indirildiği düşünülmektedir.

Sekil 2b'de atık yakıt kullanımıyla $\mathrm{Cr}$ konsantrasyon değerlerinin değişimleri gösterilmektedir. Klinkerin ham maddelerinden olan kilden, çimentoya küçük bir miktar $\mathrm{Cr}$ girişi olmaktadır. Referans çimento numunesinden çevreye salınan $\mathrm{Cr}$

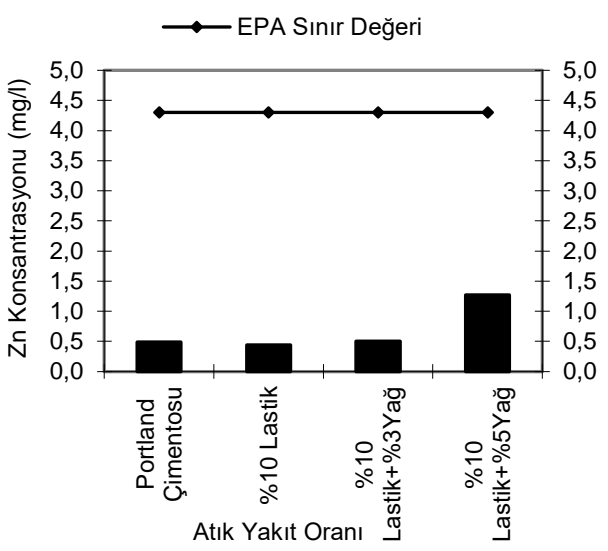

a)

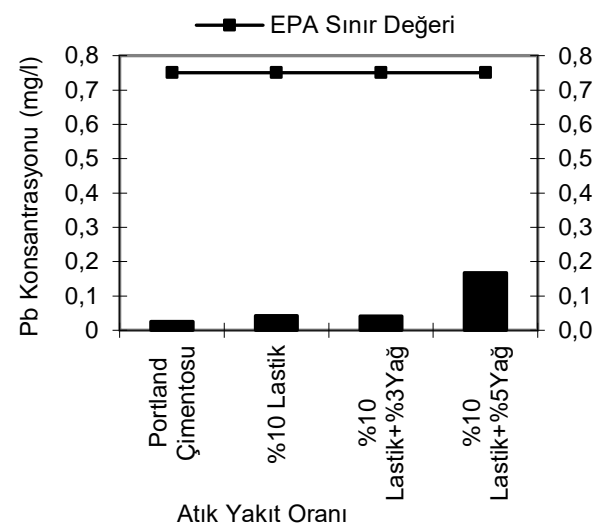

c)

Şekil 2.Sızıntısuyundaki ağır metal konsantrasyonları a)Zn b) $\mathrm{Cr}$ c) $\mathrm{Pb}$ d) $\mathrm{Cd}$ miktarı yaklaşık 0,05 mg/l'dir. Atık lastik kullanımıyla, numuneden sızan $\mathrm{Cr}$ miktarında kayda değer bir değișim görülmemiştir. Atık lastik $\mathrm{Cr}$ içermediği için sızıntı suyundaki $\mathrm{Cr}$ konsantrasyonunda artış olmaması beklenen bir sonuçtur. \%5 oranında atık yağın kullanımıyla, yağın Cr içeriğinden dolayı sızıntı suyuna geçen miktar $0,05 \mathrm{mg} / \mathrm{l}$ 'den $0,1 \mathrm{mg} / \mathrm{l}$ seviyelerine çıkmış, buna rağmen USEPA sınır değeri olan 0,6 mg/l'nin altında kalmıştır. $\mathrm{Cr}$, ilk hidratasyon ürünü olan etrinjit (AFt) içerisindeki Al ile yer değiştirmek suretiyle AFt yapısına girebilmektedir.

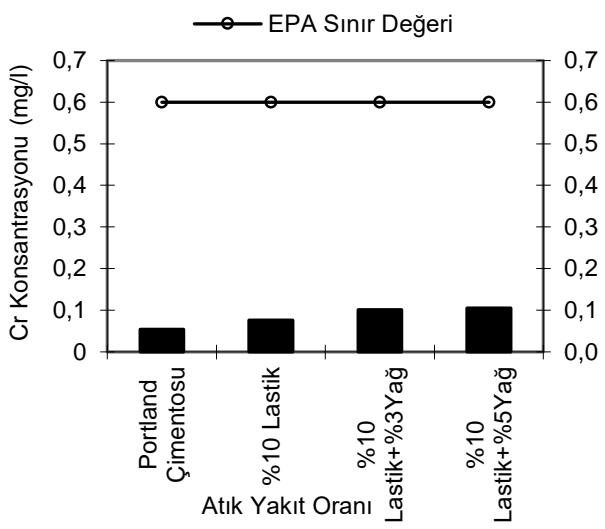

b)

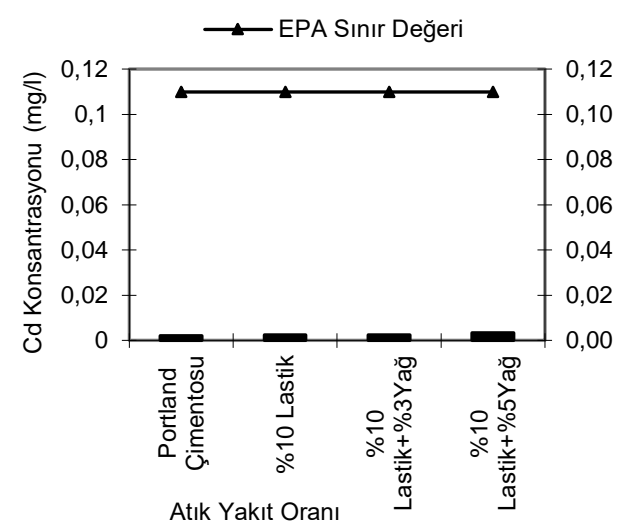

d) 
Atık lastik kullanımıyla sızıntı suyundaki $\mathrm{Pb}$ miktarında kayda değer bir artış gözlenmezken $\% 5$ atık yağ kullanımıyla, 0,025 $\mathrm{mg} / \mathrm{l}$ 'den $0,16 \mathrm{mg} / \mathrm{l}$ 'ye çıktığı ve buna rağmen tüm numunelerdeki konsantrasyonunların USEPA sınır değeri olan $0,75 \mathrm{mg} / \mathrm{l}$ 'nin altında kaldığı görülmüştür (Şekil $2 \mathrm{c}$ ). Pb, çimento hidratasyonu sonrasinda hidroksit formunda bulunur [20]. Pb, hidratasyon sirasinda, C-SH'ın yapısına girmemekte, fazın yüzeyinde $\mathrm{Pb}(\mathrm{OH})_{2}$ çökeleği olușturarak diğer bir deyişle $\mathrm{C}-\mathrm{S}-\mathrm{H}$ 'a dışarıdan bağlanmak suretiyle (Pb-C-SH) tutulmaktadır [24]. Çalışmamızda, Pb'un hidroksit formunda C-S-H'a dışarıdan bağlanıp çevreye taşınımının engellendiği düşünülmektedir. Şekil 2 d'de atık lastik ve yağ kullanımıyla konsantrasyon-larındaki değişim gösterilmiştir. Çalışmamızda, referans çimento numunesinden sizıntı suyuna geçen $\mathrm{Cd}$ konsantrasyonu $0,002 \mathrm{mg} / \mathrm{l}$ olarak ölçülmüștür. Atık lastik kullanımıyla Cd konsantrasyonlarında herhangi bir artış olmamış ancak atık lastikle birlikte \%5 oranında atık yağın kullanılmasıyla Cd konsantrasyonunun $0,034 \mathrm{mg} / \mathrm{l}$ 'ye çıktığ görülmüștür. $\mathrm{Bu}$ artıșa atık yağın $0,2 \mathrm{mg} / \mathrm{l}^{\prime}$ lik Cd içeriğinin sebep olduğu düşünülmektedir. Tüm numunelerde Cd konsantrasyonu 0,11 $\mathrm{mg} / \mathrm{l}$ sınır değerinin altında kalmıştır.

\section{Sonuç}

- Atık lastik ve atık yağın ikincil yakıt olarak kullanımının klinkerin kimyasal kompozisyonunda ve mineral faz dağılımında kayda değer bir değişime sebep olmadığı görülmüştür.

- Atık lastik, çimentonun 3 günlük basınç dayanımı değerlerini \%30 düşürürken atık yağ kullanımı ortalama \%30 arttırmıştır. Atık lastiğin Zn içeriğinin hidratasyonu geciktirerek kısa vadede basınç dayanımının düşmesine neden olduğu, atık yağın $\mathrm{Cr}$ içeriğinin de hidratasyonu hızlandırarak basınç dayanımı gelişimini olumlu etkilediği sonucuna varılmiștır.

- 56 gün sonunda tüm numunelerin basınç dayanımı değerleri, referans Portland çimentosu numune sonuçlarına ulaşmış olup, uzun vadede atık lastik ve atık yağ kullanımının çimentonun basınç dayanımı gelişimini olumsuz etkilemediği görülmüştür.

- Atık lastik ve atık yağ kullanılarak üretilen çimentolardan sızıntı suyuna geçen $\mathrm{Zn}, \mathrm{Cr}, \mathrm{Pb}$ ve $\mathrm{Cd}$ konsantrasyonlarının USEPA atık depolanabilirliği sınır değerlerinin altında kaldığı ve üretilen çimentoların tehlikelilik özelliği taşımadığı görülmüştür.

- Atık lastik ve atık yağın çimento üretiminde ikincil yakıt olarak kullanımının, gerek çimentonun özelliklerine gerekse çevreye olumsuz bir etkisinin bulunmadığı sonucuna varılmıştır.

\section{Kaynakça}

[1]Twigger, L., Rithie, A., Hudson, B., Laban, K., Davies, C. 2003. Katı Atık Kaynaklı Yakıtların Çimento ve Kireç Fırınlarında Kullanılması, TÇMB.

[2] Richardson, A. 1995. Hazardous Waste Combustion in Cement Kilns. An Introduction to Policy and Legal Issues Associated with Burning Hazardous Waste in Cement Kilns. A Briefing Paper of the American Lung Association Hazardous Waste Incineration Project. VI. Regulation of Hazardous Waste in Cement Kilns- 40 CFR

[3]Pipilikaki, P., Katsıotı, M., Papgeorgıou, D., Fragou, D., Chanıotakıs,Ü E. 2005. Use of Tire Derived Fuel in Clinker Burning. Cement \& Concrete Composites, Cilt, 27, s. 843-847

[4]European Commision-Directorate General Environment Refuse Derived Fuel, Cement Practice and Perspectives - Final Report, 2003. B4-3040/2000/306517/MAR/E3.

[5]Mokrzycki, E., Bochenczyk, A.U. 2003. Alternative Fuels for the Cement Industry, Applied Energy, Cilt,74, s.95-100.

[6]Freitas S.S., Nóbrega C.C. 2014. Os benefícios do coprocessamento de pneus inservíveis para a indústria cimenteira,The benefits of co-processing wasted tires for the cement industry, Eng Sanit Ambient, Cilt.19, s. 293-300.

[7]Dominguez A., Lopez-Ayala F., RomeroCardenas J., Erika 2017. Energetic utilization of waste oils and their contribution to environmental sustainability through 
DEÜ FMD 22(66), 851-859, 2020

processing in cement kilns, CIENCIA UNEMI, Cilt. 10 s. 51-64.

[8]Basel Convention Technical Guidelines on the Identification and Management of Used Tyres, Basel Convention Series SBC No. 02/10, 1999.

[9] USEPA 2005. 530-F-05-006 Tire Derived Fuel (TDF)

[10]Atıkların Ek Yakıt Olarak Kullanılmasında Uyulacak Genel Kurallar Hakkında Tebliğ, Resmi Gazete, Sayı: 25853. 2005.

[11] Atık Yağların Kontrolü Yönetmeliği, Çevre ve Orman Bakanlığı, Resmi Gazete, Sayı: 25353, 2004.

[12] Trezza M. A., Scian A. N. 2000. Burning Wastes as an Industrial Resource: Their Effrct on Portland Cement Clinker, Cement and Concrete Research, Cilt. 30, s.137-144.

[13] Nakomcic-Smaragdakis B. ,Cepic Z., Senk N. , Doric \& Lj J., Radovanovic 2016. Use of scrap tires in cement production and their impact on nitrogen and sulfur oxides Emissions, Energy Sources, Part A: Recovery, Utilization, and Envıronmental Effects, Cilt.38, s. $485-493$.

[14] Gabel, K., Tillman, A. M. 2005. Simulating Operational Alternatives for Future Cement Production, Journal of Cleaner Production, Cilt.13, s.1246-1257.

[15] Trezza M. A., Scian A. N. 2004. Waste Fuels: Their Effect on Portland Cement Clinker, Cement and Concrete Research, Cilt.35, s.438444.

[16]Tehlikeli Atıkların Kontrolü Yönetmeliği (TAKY), 2005. Çevre ve Orman Bakanlığı, Resmi Gazete, Sayı: 25755.

[17] ASTM C 778-87, 1989. Standard Specification for Standard Sand. Annual Book of ASTM Standards Section 4. Construction: Philadelphia, PA 19103-1187 U.S.A. Vol. 04.01, 333-334.

[18]Ünlü, H., 2006. Otomotiv Endüstrisinde Oluşan Tehlikeli Atıkların Geri Kazanımı, Yüksek Lisans Tezi, Uludağ Üniversitesi Fen Bilimleri Ensititüsü, Bursa

[19] Neville, A.M. 1981. Properties of Concrete. 3rd Edition. ISBN: 0-582-40626-9, Longman
House, Burnt Mill, Harlow, Essex CM202JE, England.

[20]Conner, J.R. 1990. Chemical Fixation and Solidification of Hazardous Wastes. Van Nostrand Reinhold, New York.

[21]Hamilton, I. W., Sammes, N. M. 1999. Encapsulation of Steel Foundry Bag House Dusts in Cement Mortar, Cement Concrete Research, Cilt. 29, s. 55-61.

[22]Asavapisit, S., Fowler, G., Cheeseman, C.R. 1997. Solution Chemistry During Cement Hydration in the Presence of Metal Hydroxide Wastes, Cement Concrete Research, Cilt.27, s.1249-1260.

[23]USEPA, 1999. Land Disposal Restrictions Phase II- Universal Treatment Standards, and Treatment Standards For Organic Toxicity Characteristics Wastes And Newly Listed Wastes, Final Rule, Title 40 Federal Regulations (CFR), 7-1-99 Edition, Part 268.

[24]Thevenin, G., Pera, J. 1999. Interactions Between Lead and Different Binders, Cement and Concrete Research, Cilt.29, 1605-1610. 